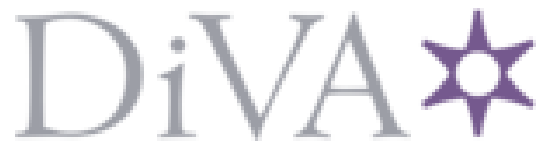

http://www.diva-portal.org

Postprint

This is the accepted version of a paper presented at EGU General Assembly 2021.

Citation for the original published paper:

Gál, C V. (2021)

Urban weather generation: the intercomparison of three emerging models In:

https://doi.org/10.5194/egusphere-egu21-16001

N.B. When citing this work, cite the original published paper.

Permanent link to this version:

http://urn.kb.se/resolve?urn=urn:nbn:se:du-37547 


\section{Urban weather generation: the intercomparison of three emerging models}

Csilla V Gál (cga@du.se), Dalarna University, Sweden

Aim: to assess the performance of three numerical simulations models in reproducing urban air temperature at the local scale.

\section{Field experiment:}

- August 3-17, 2013

- Two Ta/RH data loggers (T2, T3)

- Neighborhood of Újlopótváros, Budapest

\section{Models:}

- Urban Weather Generator (UWG)

- Vertical City Weather Generator (VCWG)

- Surface Urban Energy and Water Balance Scheme (SUEWS)

\section{Forcing:}

- weather station data (from OMSZ)

- ERA5 (for SUEWS)

Weather station sites: (1) Újpest and (4) Pestszentlőrinc Filed onbservation sites: T2 and T3

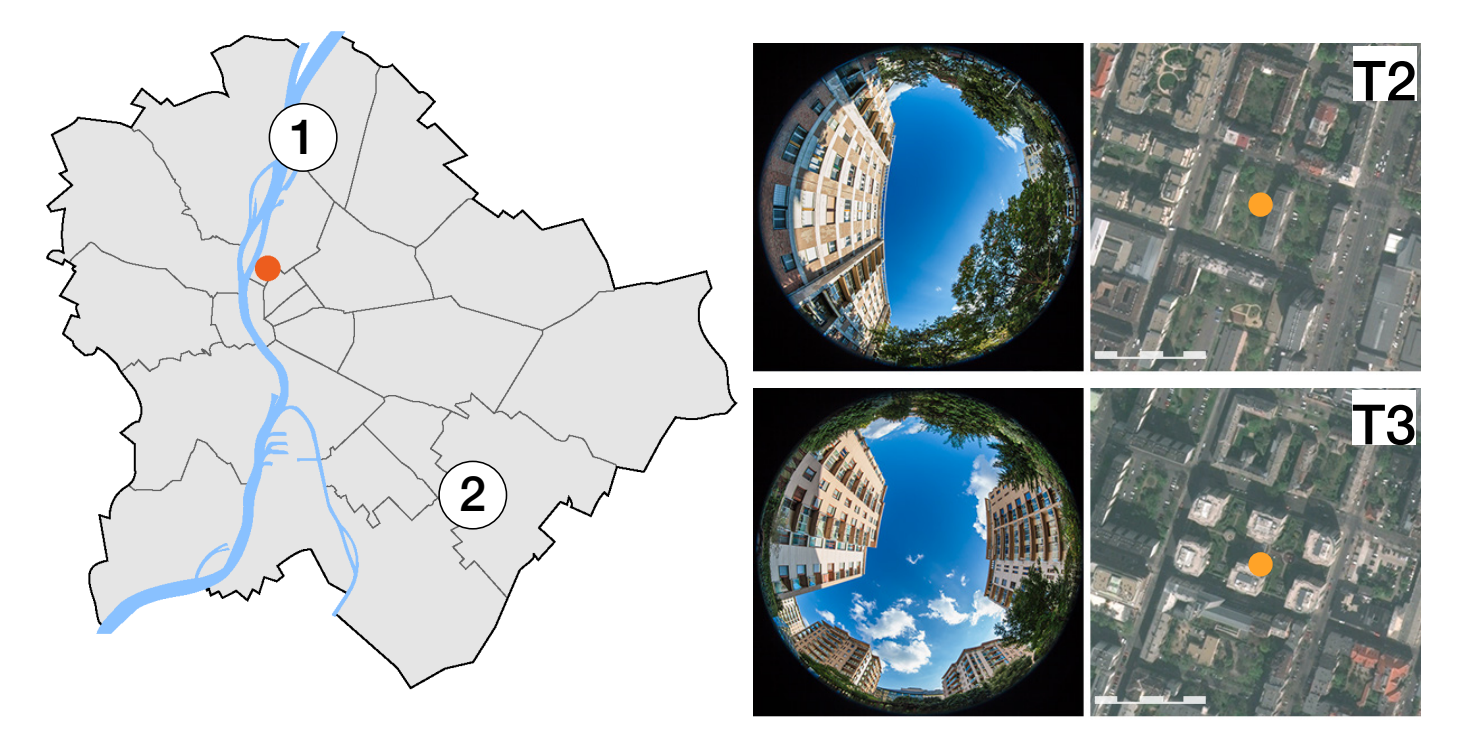

(A)

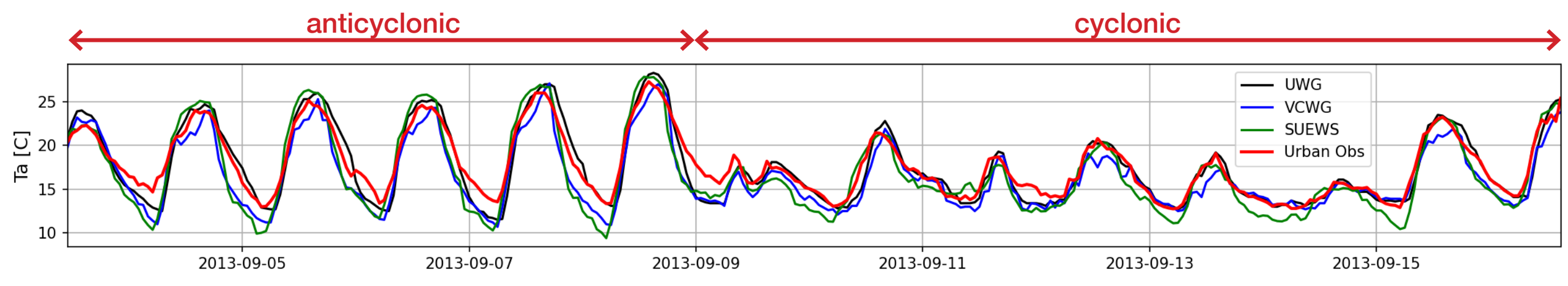

(B)
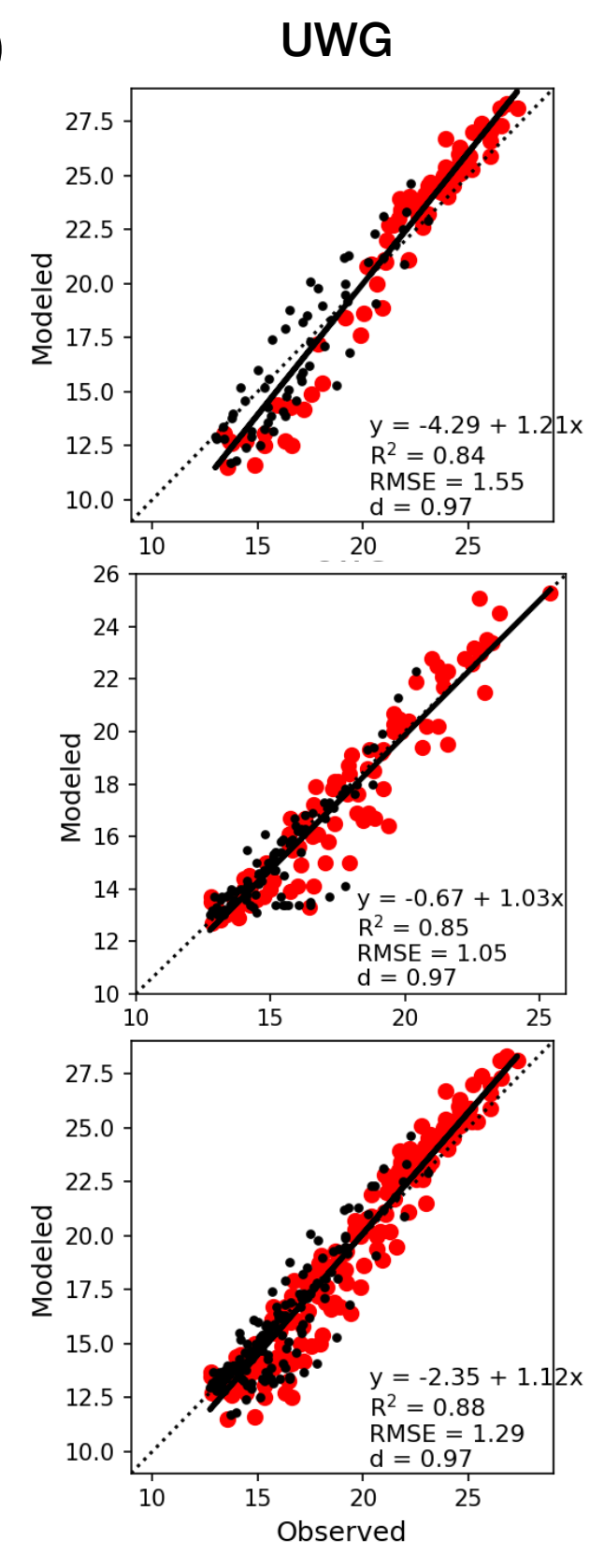

VCWG
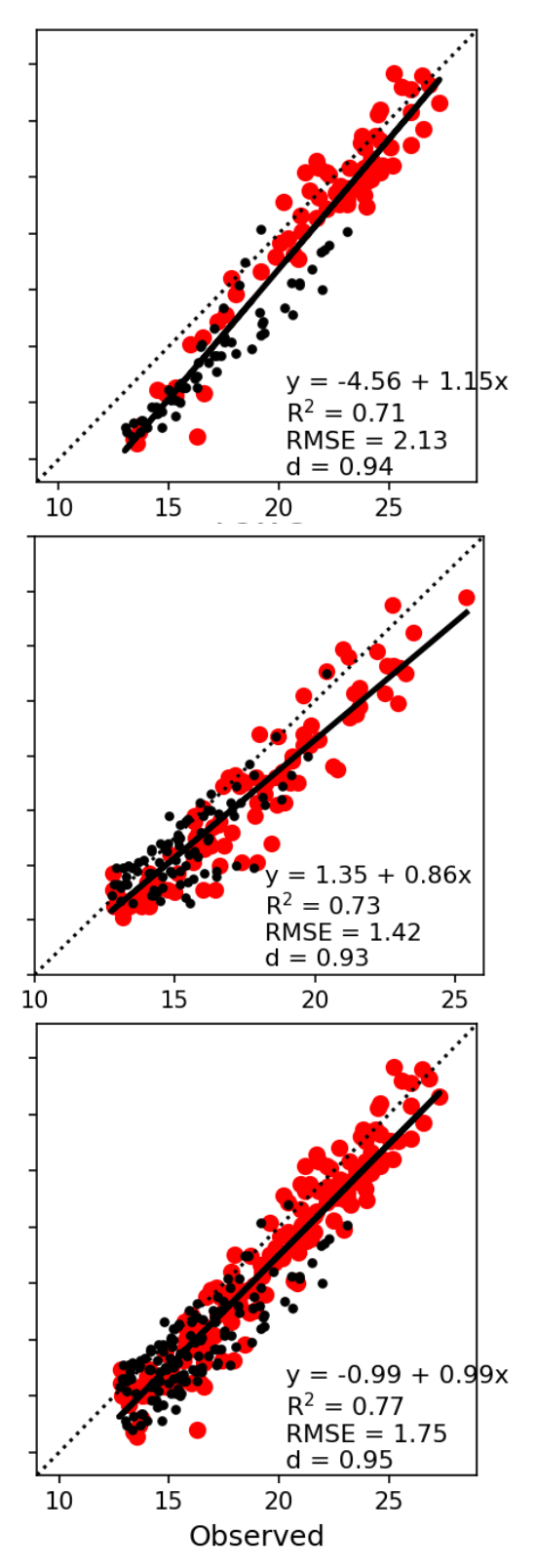

SUEWS
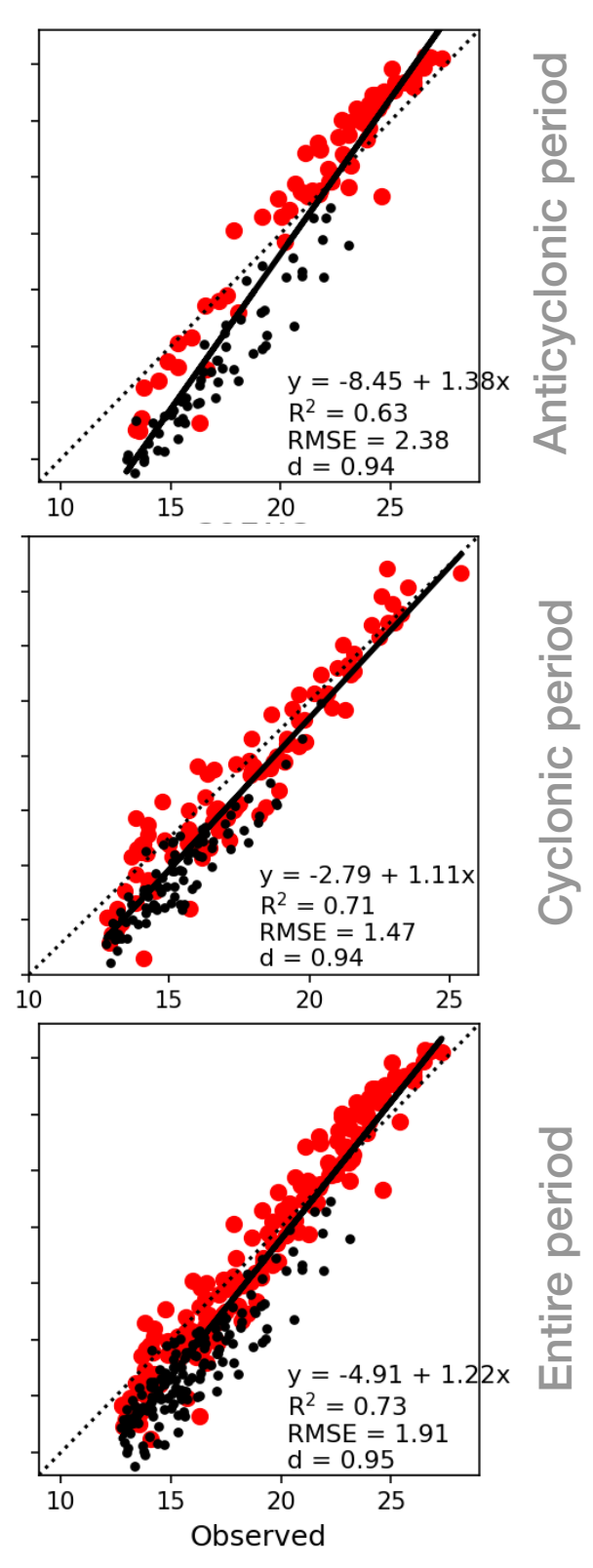

Evolution (A) and scatter plots (B) of observed and modeled hourly urban air temperature values

Preliminary results:

Especially during anticylonic periods, models tend to underestimate nighttime temperatures.

Anticyclonic period
\begin{tabular}{|l|r|r|r|}
\hline & UWG & \multicolumn{1}{c|}{ VCWG } & SUEWS \\
\hline RMSE & 1.55 & 2.13 & 2.38 \\
\hline d & 0.97 & 0.94 & 0.94 \\
\hline
\end{tabular}

Entire period

\begin{tabular}{|l|r|r|r|}
\hline & UWG & VCWG & SUEWS \\
\hline RMSE & 1.29 & 1.75 & 1.91 \\
\hline d & 0.97 & 0.95 & 0.95 \\
\hline
\end{tabular}

Acknowledgement.

The author would like to thank the Hungarian Meteorological Services (OMSZ) for the data provided.

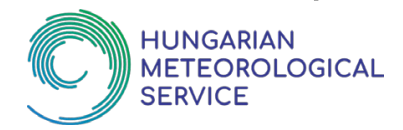

DALARNA 